\title{
La buena fe como parámetro jurídico para identificar la modalidad emptio spei o emptio rei speratae en el contrato de compraventa de cosa futura
}

\author{
Good faith as legal parameter to identify the type emptio spei or \\ rei emptio speratae in the contract of sale of future thing
}

José Vicente Hurtado Palomino

Abogado por la Universidad Santo Tomás Bucaramanga (Col.); especialista en Derecho Comercial y magister en Derecho Comercial por la Universidad Externado de Colombia (Col.); magíster (en curso) en Derechos Fundamentales y Libertades Públicas, Universidad de Castilla, La Mancha, España; docente investigador grupo de investigación Neoconstitucionalismo y Derecho de la Universidad Santo Tomás Bucaramanga (Col.).

Correo electrónico: angeledei@hotmail.com

\begin{abstract}
Resumen
Desde una arista sociológica, el contrato compraventa de cosa futura se ha consolidado en el ámbito agroempresarial, toda vez que facilita una serie de beneficios desde el punto de vista financiero, técnico o de simple conveniencia, para quienes lo empleen con el propósito de comercializar o comprar frutos futuros. Desde el punto de vista jurídico, el citado tipo contractual es reconocido en el ordenamiento jurídico colombiano y se clasifica según su objeto recaiga en el álea o esperanza de la existencia futura de un bien o en la cosa esperada que al momento del perfeccionamiento es inexistente, pero que en el futuro va a existir en una alta probabilidad. La primera modalidad de contrato ostenta el carácter de aleatorio y la segunda es de naturaleza conmutativa.

Sin embargo, las normas que lo reglamentan no establecen una solución clara en el evento en que las partes no plasman de manera diáfana en el contenido del negocio jurídico la especie de compraventa de cosa futura que realizaron.

Para resolver la problemática antes reseñada, el presente escrito plantea como parámetro jurídico para identificar la modalidad de contrato de compraventa de cosa futura el principio de la buena fe.
\end{abstract}

Palabras clave: Buena fe, compraventa de cosa esperada, compraventa de la esperanza, aleatorio, conmutativo.

\begin{abstract}
From a sociological angle, the buying and selling contract of future products has been consolidated in the agrobusiness field, as long as it facilitates a series of benefits from a financial, technical, or simply a convenience point of view for those who intent to use it with the purpose of commercialize or to buy future produce.

From a legal point of view, the contract type previously mentioned is recognized in the Colombian law and it is classified according to the level of uncertainty of the future existence of the produce, which at the moment when the contract takes place it is nonexistent but there is a high probability of its existence in the future. The first classification is of aleatory nature and the second one is of commutative nature.

Nevertheless, the laws that regulate them do not establish a clear solution in the event that the parties do not specify the type of buying and selling contract that took place in the negotiation.

In order to solve the issue previously discussed, the present document suggests as a parameter to identify the type of buying and selling contract of future product the principle of good faith.
\end{abstract}

Keywords: Good faith, buying and selling of expected product, buying and selling of hope, aleatory, commutative. 


\section{Résumé}

D'un bord sociologique, la vente de contrat de chose future a été consolidée dans le domaine agro-alimentaire, car il fournit un certain nombre d'avantages du point de vue de la commodité financière, technique ou simple pour ceux qui l'utilisent à des fins de marketing ou de acheter à terme les fruits.

Du point de vue juridique, le taux contractuel mentionné ci-dessus est reconnu dans le système juridique colombien et est classé en fonction de son objet tombe à Alea ou espoir pour l'existence future d'un puits ou la chose espère que lorsque l'amélioration est inexistante, mais à l'avenir existera dans une forte probabilité. Le premier type de contrat détient le caractère aléatoire et la seconde est la nature commutative.

Toutefois, les règles qui régissent pas fournir une solution claire dans le cas où les parties ne le font pas, nous avons réfléchi clairement dans le contenu de l'entreprise juridique du genre de vente de chose future qu'ils ont fait. Pour résoudre les problèmes décrits ci-dessus, le présent document pose comme un paramètre juridique pour identifier le type de contrat pour la vente de chose future du principe de bonne foi.

Mots-clés: Bonne foi, achat de chose prévu, les ventes de l'espoir, au hasard, commutative. 


\section{La buena fe como parámetro jurídico para identificar la modalidad emptio spei o emptio rei speratae en el contrato de compraventa de cosa futura*}

José Vicente Hurtado Palomino

\section{INTRODUCCIÓN}

En el escenario de los negocios agroempresariales es frecuente la utilización del contrato de compraventa de cosa futura para la comercialización de los frutos que provienen de los cultivos, en razón a que dicho instrumento contractual le permite al vendedor ofrecer tales bienes a un precio competitivo, efectuar un plan estratégico orientado a la financiación y a la distribución de los mismos en el menor tiempo posible, entre otros factores. De otro lado, el citado negocio jurídico le conviene al comprador, toda vez que le ayuda a fidelizar un vendedor, le da un tiempo prudencial para completar el monto total del precio a través de solicitudes de crédito ante entidades bancarias, entre otras razones.

En razón a la trascendencia de este contrato en las relaciones comerciales, ha sido reconocido en el ordenamiento jurídico colombiano bajo las especies de venta de la esperanza (emptio spei) o venta de la cosa esperada (emptio rei speratae). La primera modalidad de naturaleza aleatoria y la segunda de carácter conmutativo.

No obstante, las normas que reglamentan el anterior contexto negocial, no establecen una solución clara en el evento en que las partes omiten establecer por medio del acuerdo la modalidad de contrato de compraventa de cosa futura.

Para resolver tal problemática, el presente escrito aborda de manera breve el contenido del principio de la buena fe; luego analiza la naturaleza conmutativa o aleatoria del contrato de compraventa de cosa futura según sus modalidades, a partir de la Teoría General del Contrato y del Negocio Jurídico; y por último, expone los argumentos jurídicos que sirven de base para señalar que la buena fe es un parámetro idóneo en la identificación de la especie de contrato de compraventa de frutos futuros cuando las partes no lo señalaron de manera clara.

El estudio conceptual antes descrito se realiza a partir del análisis de un caso concreto en el cual se evidencia la problemática esbozada en los párrafos precedentes.

* El presente texto se deriva del trabajo de investigación denominado "Los requisitos para que una cosa que se espera que exista sea objeto del contrato de compraventa", del Grupo de Investigación Neoconstitucionalismo y Derecho de la Facultad de Derecho de la Universidad Santo Tomás Bucaramanga. Investigador principal: José Vicente Hurtado Palomino. Coinvestigador: Gustavo Andrés Chía Cáceres. Auxiliar de Investigación: Diovanel Pacheco Arévalo. 


\section{CASO CONCRETO}

Una situación que se puede presentar en el contexto del contrato de compraventa de cosa futura es aquella en que las partes desconocen si el negocio jurídico que suscribieron se ubica en la modalidad de venta de cosa esperada (emptio rei speratae) o en la especie de venta de la esperanza (emptio espei), en razón a que ellas no tuvieron la precaución de asumir una carga de claridad (Hinestrosa, 1986) al ejercer su autonomía privada de señalar si el aludido tipo contractual se adecuaba a alguna de las citadas categorías.

Para comprender dicha situación, se trae a colación el caso de la compraventa de frutos futuros, en la que el vendedor es un empresario agroindustrial que se limitó a señalarle al comprador que le vendía la totalidad de los frutos que produjeran sus cultivos debidamente individualizados o singularizados en su predio, a un precio determinado y este último aceptó pagando por anticipado la totalidad del precio en ese mismo momento. Posteriormente, un hongo, que se estaba propagando en la zona donde estaban los cultivos para la fecha del negocio, afectó ostensiblemente las plantas e impidió la cosecha de sus frutos.

Atendiendo el caso hipotético esbozado en el párrafo precedente, se evidencia que las partes contrataron sobre una cosa futura, lo cual permite plantear varias situaciones: La primera, el vendedor puede alegar que sobre esta relación contractual se presentó un determinado objeto, que le da el derecho de expresarle al comprador que las pérdidas generadas por el deterioro del cultivo radican en cabeza de este último, en la medida en que el contrato giró en torno a una cosa futura por esperanza (Rogel, 1975) el cual se cataloga como aleatorio, y en virtud de ello, el comprador es quien debe asumir cualquier pérdida por los posibles imprevistos que afectaran la existencia de la cosa, por ejemplo, la no devolución del precio pagado.

La segunda, el comprador podría alegar un incumplimiento del contrato de compraventa de cosa futura por parte del vendedor, toda vez que dicho negocio jurídico se ubica dentro de la modalidad de venta de cosa esperada, en ese sentido, por ser un contrato conmutativo, el vendedor estaba obligado a tomar las medidas razonables dirigidas a que la cosa exista. En ese orden de ideas, el riesgo de la inexistencia de los frutos, que imposibilitaría la obligación de entrega en cabeza del vendedor, no sería trasladado al comprador, quien ante el incumplimiento de su otro extremo negocial, es titular del derecho de accionar, ya sea a través de una acción de cumplimiento, resolutoria o indemnizatoria (Rogel, 1975).

Como se puede apreciar, el caso planteado genera un problema jurídico para quienes lo realizan, y que a través del presente escrito se pretende resolver. Para tal propósito, se aborda de manera sucinta el contenido del principio de la buena fe; posteriormente se analiza la naturaleza conmutativa o aleatoria del contrato de compraventa de cosa futura según sus especies, a partir de la Teoría General del Contrato y del Negocio Jurídico; y por último se exponen los argumentos jurídicos 
que sirven de base para señalar que la buena fe es el parámetro idóneo en la determinación de si la relación contractual gira en torno a una venta de cosa esperada (emptio rei speratae) o una venta de la esperanza (emptio spei).

\section{METODOLOGÍA}

El presente texto parte de un caso concreto ${ }^{1}$ en el cual se evidencia la problemática en que se pueden encontrar los extremos negociales de un contrato de compraventa de cosa futura, cuando ellas no pueden distinguir si esta se califica bajo la modalidad de venta de cosa esperada (emptio rei speratae) o se amolda a la especie de venta de la esperanza (emptio espei).

Para resolver la situación descrita, la ponencia se basa en el estudio riguroso de las fuentes formales del derecho (ley, jurisprudencia y doctrina), con el propósito de exponer los argumentos jurídicos que explican porque la buena fe se constituye como parámetro que permite establecer la modalidad de contrato de compraventa de cosa futura que llegaron a realizar las partes.

En ese orden de ideas, el enfoque a usar es el cualitativo, orientado a realizar el estudio del problema jurídico a partir del análisis de un caso, la ponencia es un avance de una investigación de tipo jurídico-descriptiva, el método general de investigación usado es el analítico, y el método de interpretación del derecho el dogmático-jurídico, toda vez que en su desarrollo se estudian las normas jurídicas (reglas, principios y valores) que regulan los subtemas o ejes temáticos enunciados en el párrafo precedente (buena fe, compraventa de cosa esperada, compraventa de la esperanza, aleatorio, conmutativo), que se constituyen como punto clave para comprender la solución al problema jurídico antes aludido.

\section{EL PRINCIPIO DE LA BUENA FE CONTRACTUAL}

En primer lugar, es importante señalar que la buena fe que se estudia en el campo de las relaciones contractuales, es aquella que se denomina como objetiva ${ }^{2}$, la cual es entendida como la actitud de cooperación orientada a cumplir de modo positivo la expectativa de la otra parte; actitud que se resalta por la confianza, la fidelidad, el

1 El punto más importante en el examen de la tópica lo constituye la afirmación de que se trata de una técnica del pensamiento que se orienta hacia el problema (Viehweg, 1969, p. 49).

2 (...) la buena fe objetiva encuentra consagración en el artículo 1546 del Código Civil chileno, artículo 1603 del C. C. colombiano, conforme al cual "los contratos deben ejecutarse de buena fe, y por consiguiente obligan no solo a lo que en ellos se expresa, sino a todas las cosas que emanan precisamente de la naturaleza de la obligación o que por ley pertenecen a ella", de donde se desprende que la buena fe objetiva se manifiesta claramente como un deber de comportamiento, que exige para predicar la buena fe del agente que este adecúe de manera efectiva su conducta a las reglas que emanan del principio, por oposición al mero estado de conciencia a que alude el artículo 768 refiriéndose a la buena fe subjetiva (Neme, 2009, p. 52). 
compromiso, la capacidad de sacrificio, la prontitud de ayudar a la otra parte y, en lo concerniente a los tratos preparatorios del contrato, la lealtad y la veracidad hacia el otro extremo negocial (Betti, 1969).

Aunado a lo precedente, se considera que la buena fe es un principio (Larenz, 1978) que busca aportar al mejoramiento en las relaciones entre las personas, lo cual no es posible "sin que la confianza dispensada, al menos en general, no sea defraudada sino confirmada, y que, por ello la buena fe permanezca como posible en cuanto fundamento de relaciones humanas" (Larenz, 1978, pp. 58-59).

Para cumplir el citado propósito, el principio de la buena fe ejerce una fuerza en las relaciones jurídico-negociales en una triple dirección de la siguiente manera:

a. En primer lugar se dirige al deudor, con el mandato de cumplir su obligación, ateniéndose no solo a la letra, sino también al espíritu de la relación obligatoria correspondiente -en especial conforme al sentido y la idea fundamental del contrato - y en la forma en que el acreedor puede razonablemente esperar de él.

b. En segundo lugar, se dirige al acreedor, con el mandato de ejercitar el derecho que le corresponde, actuando según la confianza depositada por la otra parte y la consideración altruista que esta parte pueda pretender según la clase de vinculación especial existente.

c. En tercer lugar, se dirige a todos los participantes en la relación jurídica en cuestión, con el mandato de conducirse como corresponda en general al sentido y finalidad de esta especial vinculación y a una conciencia honrada (Larenz, 1958, p. 148).

Por otro lado, cabe resaltar que las partes en ejercicio de su autonomía contractual no pueden renunciar o suprimir el referido principio a través de una cláusula accidental contenida en el respectivo negocio jurídico, pues ella se cataloga como de orden público (Corte Constitucional, 1992) e irrenunciable atendiendo lo dispuesto por los artículos 15 y 16 del Código Civil. Tales características que limitan su disposición en las relaciones inter privados "conduce a que la buena fe se imponga sobre las previsiones contractuales cuando estas quebranten el [citado] principio" (Neme, 2006, p. 89).

Expuestos los conceptos que la doctrina ha señalado de la buena fe, como un elemento ético-social en general, a continuación se revisa el reconocimiento del citado principio en la Constitución Política y se explica su desarrollo en el derecho privado colombiano en el ámbito legal y jurisprudencial.

\section{La buena fe en el ordenamiento jurídico colombiano}

El principio de la buena fe contractual está contemplado en el artículo 83 de la Constitución Política, donde reza que los particulares como partes en las relaciones 
negociales "deberán ceñirse a los postulados de la buena fe"3. En concordancia con la aludida norma constitucional, el artículo 871 del Código de Comercio señala que "los contratos deberán celebrase y ejecutarse de buena fe", por su parte, el artículo 1603 del Código Civil estipula que "los contratos deben ejecutarse de buena fe" estableciendo la obligación de actuar con diligencia, prudencia, en pro de un favorecimiento mutuo durante el desarrollo del contrato.

A partir de lo anterior, la Sala de Casación Civil de la Corte Suprema de Justicia ha señalado en su jurisprudencia que la buena fe se caracteriza por ser bifronte, bipolar y plurifásica (CSJ, 2001).

\section{Características de la buena fe}

La buena fe es bifronte porque ella:

se desdobla, preponderantemente para efectos metodológicos, en la apellidada 'buena fe subjetiva' (creencia o confianza), al igual que en la 'objetiva' (probidad, corrección o lealtad), sin que por ello se lesione su concepción unitaria que, con un carácter más panorámico, luce unívoca de cara al ordenamiento jurídico (CSJ, 2001).

Por otra parte, la buena fe contractual se cataloga como bipolar, en razón a que ella debe ser cumplida por todos los sujetos que intervienen en el contrato, es decir, independientemente del rol (deudor o acreedor) que tenga cada extremo negocial, todos están obligados a cooperar entre sí para el cumplimiento de sus obligaciones. Por tal razón, se afirma que "[e]n la ciencia jurídica desde hace tiempo se viene consolidando la idea que la relación contractual no sólo consiste en exigencias contrapuestas, sino que origina ciertos deberes de cooperación, conforme al principio de la buena fe" (San Martín, 2011, p. 277).

Por último, el carácter plurifásico del mencionado principio hace referencia a que este se desarrolla a lo largo de las distintas fases del contrato en lo que tiene que ver "a la formación del negocio jurídico, lato sensu (fase formativa o genética), la

3 La lectura del citado artículo 83 genera varios interrogantes: el primero de ellos acerca del tipo de buena fe que la norma dispone presumir. En general la buena fe que se exige a los administrados en los trámites ante la administración es objetiva, en cuanto que lo que se valora es si el comportamiento de los particulares frente a la administración se adecua a los deberes que impone el principio y no una simple creencia o estado psicológico acerca de la conformidad con los mismos. Vale decir: se presumirá la lealtad, la honestidad, la fidelidad, la corrección, la ausencia de dolo, entre otros, bajo el entendido de que esas son las conductas objetivas que deben esperarse usualmente de los administrados. (...) No encontramos en principio que exista campo de aplicación para la presunción de buena fe subjetiva dentro de las relaciones de los particulares con la administración en cuanto se refiere a la realización de gestiones de los administrados frente a aquella, esto es, eventos en los que resulte razonable amparar la mera creencia o convicción psicológica del administrado de no estar lesionando derecho alguno; aquel que parecería el más propicio: el de la ignorancia de la ley -error de derecho- ha sido descartado por la ley y la Corte Constitucional ha avalado la conformidad de tal norma frente al principio de buena fe, como se expuso precedentemente (Neme, 2010, p. 88). 
relativa a su celebración (fase de concreción o de perfeccionamiento) y la referente a su desenvolvimiento, una vez perfeccionado (fase ejecutiva; de consumación o postcontractual)" (CSJ, 2001).

Revisadas las características de la buena fe que han sido reconocidas por la jurisprudencia de la Sala de Casación Civil de la Corte Suprema de Justicia y la doctrina, de manera seguida se abordan las funciones que cumple el mencionado principio.

\section{Funciones de la buena fe contractual}

La doctrina ha señalado que el principio de la buena fe contractual tiene tres funciones denominadas: interpretativa (Arrubla, 2007), integradora (Betti, 1969) y correctiva (Larenz, 1958), las cuales se deducen de la lectura de los ya citados artículos 871 del Código de Comercio y 1603 del Código Civil.

\section{a. Función interpretativa}

La buena fe objetiva parte de la naturaleza jurídica del contrato y señala los parámetros por los cuales dicho negocio jurídico se debe ejecutar, al indicar a las partes las obligaciones que deben cumplir. De esta manera, surge una sinergia entre la autonomía contractual, con base en la intención o declaración de los contratantes, y la naturaleza jurídica de cada negocio, que permite el despliegue de la función interpretativa de la buena fe.

En ese sentido, dicha función obliga a los intérpretes del contrato a tener en cuenta la naturaleza jurídica de este y las previsiones establecidas en los presupuestos de hecho de la norma, con el fin de determinar la manera como las partes deben actuar en la relación contractual.

En razón a lo precedente, es atinado señalar que la buena fe tiene un vínculo muy estrecho con los criterios de interpretación de los contratos consagrados en el Código Civil, pues en el evento en que no se tenga certeza sobre el término apropiado para determinar los derechos y obligaciones de las partes en el contenido del contrato, la buena fe es un factor idóneo para fijar el término más adecuado ${ }^{4}$.

Sumado a lo precedente, la buena fe contribuye a auscultar la intención de las partes $^{5}$, en el evento de valorar si la conducta que ellas van a realizar o desplegaron

4 En el contexto internacional se evidencia que el principio de la buena fe tiene una importancia mayúscula para la interpretación de los contratos. Lo anterior se refleja en los Principios para los Contratos Comerciales Internacionales de UNIDROIT, que se incorporaron en el ordenamiento jurídico colombiano a través de la Ley 32 de 1992, exequible según sentencia C-048 de 1994, en su versión 2010, en el artículo 4.8 que establece en el numeral (2) literal (c) lo siguiente: "Para determinar cuál es el término más apropiado, se tendrán en cuenta, entre otros factores (...) la buena fe y la lealtad negocial".

5 Código Civil. Artículo 1618. Conocida claramente la intención de los contratantes, debe estarse a ella más que a lo literal de las palabras. 
es ajustada o no a los propósitos negociales, pues el referido principio señala a los extremos contractuales los límites de su conducta dentro de la relación contractual ${ }^{6}$. Al respecto, la doctrina reconocida señala:

(...), la voluntad de las partes debe estar signada por el mismo principio, pero como se trata de analizar conductas humanas y "humano es errar", puede suceder que la intención de las partes haya sido establecer algo contrario a la buena fe o que se haya desviado de la función económica y social que pretendían realizar como finalidad práctica de su negocio. Allí, la buena fe, como principio hermenéutico debe corregir lo equivocado. El deber de buena fe no permite a las partes apartarse de los preceptos propios que el mismo deber implica (Arrubla, 2007, p. 360).

\section{b. Función integradora}

La buena fe contractual se constituye como un elemento integrador del contenido y efectos del negocio jurídico (Hinestrosa, 2002), en razón a que amplía "las obligaciones literalmente asumidas mediante el contrato, (...) y en la medida en los que, de hacerse valer su tenor literal, contravendrían aquel criterio" (Betti, 1969 , p. 102). Por lo anterior, “(...) las partes deben observar mucho más que un comportamiento objetivo traducido en el cumplimiento de la obligación, deben cumplir la obligación de manera adecuada y eficiente y además deben colaborar con la otra parte" (Vargas, 2001, p. 495).

En ese orden de ideas, la buena fe a través de la función integradora conecta todos aquellos elementos inherentes o de la naturaleza del contrato a la normatividad jurídica, específicamente y en mayor medida en la Teoría General del Contrato, generando una serie de obligaciones como de información, de diligencia, de lealtad y de probidad, entre otros (Neme, 2010).

Sobre esta temática, la Sala de Casación Civil de la Corte Suprema de Justicia señala que la buena fe objetiva

se traduce en una regla -o norma- orientadora del comportamiento (directiva o modelo tipo conductual) que atañe al dictado de precisos deberes de conducta que, por excelencia, se proyectan en la esfera prenegocial y negocial, en procura de la satisfacción y salvaguarda de intereses ajenos (deberes de información; de claridad o precisión; de guarda material de la cosa; de reserva o secreto, etc.) (CSJ, 2001).

$6 \quad$ Otro ejemplo en el campo internacional en que se aprecia la importancia de la buena fe en el contexto de la hermenéutica contractual está en el Código Europeo de los Contratos o también conocido Proyecto de Pavía o Gandolfi, en el numeral 4 del artículo 39 que señala: "En todo caso, la interpretación del contrato no debe conducir a un resultado contrario a la buena fe o al buen sentido". Por otro lado, los Principios del Derecho Europeo de Contratos, en el artículo 5.102 en el literal (g) se establece que "para interpretar el contrato se atenderá en especial (...) las exigencias de la buena fe". 
A continuación se realiza una descripción somera de las obligaciones de lealtad y diligencia que emanan de la buena fe contractual, toda vez que estas se reflejan o tienen repercusiones en el contrato de compraventa de cosa futura.

\section{- Obligación de lealtad}

La obligación de lealtad consiste en aquella fidelidad mutua que los extremos negociales asumen, con el fin de favorecerse recíprocamente en sus intereses, atendiendo la naturaleza del contrato. En ese sentido, se afirma que "la lealtad puede ser entendida como fidelidad de la persona hacia la persona, o bien como lealtad en el tráfico mercantil" (Neme, 2010, p. 259).

En el primer caso, se hace referencia a una lealtad que gira en torno al sujeto de derecho, quien actúa conforme a un "incondicional empeño de devoción hacia los intereses de la otra parte, como sucede en el caso de la sociedad, de la fiducia, de la tutela y del mandato" (Neme, 2010, p. 259).

En el segundo evento, no existe un vínculo entre la lealtad y la persona, más bien entre aquella y la naturaleza del tráfico mercantil, en aras de garantizar que cada negocio se ejecute conforme a un estándar de corrección, de transparencia, de claridad, de plena satisfacción de los intereses en juego que son impuestos por el tráfico mercantil como requisitos indispensables para alcanzar una más segura libertad, para ejecutar los mismos actos jurídicos (Neme, 2010).

Como expresión de esa obligación de lealtad está la obligación de información la cual hace referencia al suministro recíproco entre las partes de

informaciones concernientes a la negociación contractual, de suerte que ello les permita un claro entendimiento de todos los elementos necesarios a fin de decidir la conveniencia de la negociación en consideración a las condiciones del contrato y a las responsabilidades y derechos que de él se deriven (Neme, 2010, p. 240).

En virtud de lo precedente, se deduce que a través del cumplimiento de la obligación de información, los extremos negociales previenen cualquier confusion sobre el tipo contractual o sobre la naturaleza jurídica del contrato planeado a realizar. Es por ello que el contenido de la información debe hacer referencia a

las circunstancias, cualidades y situaciones de hecho sobre el objeto del contrato, el contenido y los efectos de este, entre otros elementos, que permiten dentro del periodo precontractual, la determinación de la decisión de contratar en las condiciones que permitan satisfacer los propios intereses de los contratantes (Chinchilla, 2011, p. 329-330).

De otro lado, sobre las características que debe tener el contenido de la obligación objeto de estudio, la Sala de Casación Civil de la Corte Suprema de Justicia en sentencia de 19 de octubre de 2009 señaló que: 
Con sujeción al postulado de la buena fe y a ineludibles deberes conexos o coligados al deber central de prestación, en especial, los de protección, transparencia e información, el vendedor está obligado a informar con claridad, precisión y a plenitud al comprador los vicios o defectos que conozca o deba conocer y, por ello, la reparación de los daños encuentra también venero en su inobservancia, por cuanto de conocerlos o haber logrado conocerlos, podía evaluarlos y abstenerse de contratar o hacerlo en términos diferentes. Tales deberes son más intensos en quienes se dedican habitual o profesionalmente a la venta, ya de manera exclusiva, concurrente o conexa con otras actividades (CSJ, 2009).

Del aludido pronunciamiento se deduce que la obligación de información, no solo tiene relación estrecha con la obligación de lealtad, sino que también tiene vínculos cercanos con la obligación de diligencia, toda vez que la intensidad de la obligación de informar varía dependiendo si el deudor de ella tiene la calidad de artifex o lego.

Aunado a lo anterior, la información que suministran las partes dentro de la relación contractual debe ser clara, oportuna, transparente y suficiente, para que cumpla los propósitos ya descritos de manera precedente.

\section{- Obligación de diligencia}

La buena fe exige que las partes asuman una conducta diligente durante todo el iter contractual, es decir, que ellas se desempeñen con total corrección frente a aquellos deberes que están unidos a la condición ética del ser humano, ser leal, honesto y respetando siempre el interés ajeno, observando la reciprocidad como aspecto fundamental en la relación contractual (Neme, 2010).

En razón a lo señalado con antelación, la diligencia que asume el deudor en una relación contractual

(...) implica no sólo no cometer imprudencias o descuidos que puedan causar efectos nocivos, sino el deber de tomar oportunas iniciativas dirigidas a evitar un daño a la otra parte o que se disminuyan los beneficios que de otra manera le habrían correspondido (Neme, 2010, p. 298).

Ahora, es importante aclarar que el concepto de diligencia si bien es cierto tiene una afinidad con la buena fe contractual, ellos no se pueden asimilar ${ }^{7}$, pues el aludido principio además de vedar a la partes el despliegue de conductas dolosas y establecer la licitud o ilicitud del comportamiento adoptado por el deudor (Cortés, 2009),

$7 \quad$ El profesor Jordano Fraga señala que: Mientras la buena fe opera en el marco general de la relación obligatoria, y se refiere, por tanto, recíprocamente a deudor y acreedor; la diligencia se refiere sólo a la posición deudora (en la que, ciertamente, pueden estar recíprocamente ambas partes) y sólo por cuanto se refiere a la actividad de cumplimiento. La diligencia es un instrumento de control de la actividad de cumplimiento del deudor, se refiere sólo al cómo de la prestación. Por tanto su papel se explica en el terreno de la responsabilidad por incumplimiento, como criterio de la misma (Jordano, 1987, p. 148). 
les obliga asumir un comportamiento correcto (Neme, 2010), así como cumplir obligaciones de solidaridad, de coherencia, de cooperación que superan el alcance del concepto de diligencia.

Por otra parte, es importante resaltar que la obligación de diligencia, se encuentra muy unida o ligada a las condiciones profesionales en las que se encuentre uno de los extremos del contrato, toda vez que al sujeto que ostente la condición de experto se le exige adoptar el modelo de artifex, generando para él un grado de diligencia mayor, toda vez que, en materia contractual, quien ostenta la mencionada condición (de artifex), debe atender y respetar "las reglas técnicas de su actividad-artificiumsin importar el grado de dificultad de ella" (Cortés, 2009, pp. 88-89, como se citó en Cannata, 1996, pp. 57-58).

El modelo de artifex se puede identificar a partir del arte de quien lo ejerce "para llegar al modelo abstracto, que será el que sirva de referencia a todos los que se ocupan de ese oficio, sin que quepa ninguna consideración especial o adicional" (Cortés, 2009, p. 89).

En suma, la diligencia no solo involucra aquella conducta de no cometer imprudencias o caer en ciertos descuidos que puedan generar efectos nocivos, sino que también contempla la obligación de tomar decisiones oportunas, que conlleven iniciativas que impliquen evitar cualquier daño que pueda sufrir la otra parte, o que en cierto modo disminuyan los beneficios que en virtud de la relación contractual le pertenecen.

En ese sentido, el vendedor responderá ante el comprador "por el escaso cuidado de la cosa vendida en el intervalo entre la celebración del contrato y la entrega efectiva de la misma, pues en dicho periodo le será exigible al vendedor una activa diligencia en el cuidado de dicha cosa" (Neme, 2010, p. 298-299).

Por último, se reitera que la obligación de información, no obstante que ella se deriva de la obligación de lealtad, tiene una relación estrecha con la obligación de diligencia, toda vez que su intensidad varía según la calidad del sujeto (artifex o lego) obligado a informar aspectos afines al contrato. En razón a lo descrito, se afirma que "[e]n aquellos eventos en que la relación contractual se establece entre un profesional y un inexperto, la obligación de informar a cargo del profesional se hace más evidente" (Chinchilla, 2011, p. 331).

\section{c. Función correctiva de la buena fe contractual}

La buena fe como criterio de valoración, eventualmente tiene el alcance de restringir aquellas obligaciones en los casos y en la medida en los que, de hacerse valer su tenor literal, la contravinieran (Betti, 1969). En ese sentido, este principio cumple una función de "corregir los excesos del pacta sunt servanda" (Soto, 2009, p. 92).

En ese orden de ideas, la función correctiva de la buena fe le señala a los extremos del contrato el camino por seguir, conforme a la naturaleza del negocio, buscando 
direccionar el actuar de las partes a los lineamientos del núcleo esencial del citado principio. La parte que no atienda lo señalado, es sujeto de una serie de sanciones jurídicas como la declaración de responsabilidad contractual con la correspondiente condena de perjuicios en la etapa de ejecución o la ineficacia parcial o total del negocio jurídico en sus modalidades (nulidad absoluta o ineficacia de pleno derecho) si su desconocimiento se dio en la etapa de formación.

De otro lado, esta función también se puede observar cuando las partes habiendo pactado algo distinto a la naturaleza jurídica del contrato respectivo, sus actuaciones se ven moldeadas o corregidas, con el propósito de encausarlas a los lineamientos del principio de la buena fe contractual (Neme, 2010).

A partir de la descripción de las funciones de la buena fe, se puede señalar que las prestaciones establecidas en sentido general en el contrato de compraventa, no se reducen a ellas, no solo porque la norma establezca otras, sino porque la buena fe contractual con base en sus funciones integradora, correctiva e interpretativa permite señalar que las partes están obligadas a cumplir con las obligaciones de lealtad, diligencia e información.

En ese orden de ideas, el vendedor y el comprador se obligan a realizar una serie de prestaciones autónomas, emanadas del aludido principio y que están ligadas a la naturaleza del contrato de compraventa, tales como el cuidado de la cosa antes de su entrega o tradición, la manifestación de las condiciones de cantidad y calidad del objeto materia del contrato, la indicación de las condiciones en que se encuentra el comprador para el pago del precio, entre otros.

Luego de abordar el concepto de buena fe atendiendo sus características, particularidades y funciones, a continuación se realiza un estudio de la determinación de la naturaleza aleatoria o conmutativa del contrato de compraventa de cosa futura, según la modalidad de venta de la esperanza (emptio spei) o de venta de la cosa esperada (emptio rei speratae), con base en la Teoría General del Contrato y del Negocio Jurídico.

\section{LA NATURALEZA CONMUTATIVA O ALEATORIA DEL CONTRATO DE COMPRAVENTA DE COSA FUTURA}

Para comprender el carácter conmutativo o aleatorio del contrato de compraventa de cosa futura, es indispensable partir de las nociones generales de la Teoría General del Contrato y del Negocio Jurídico. En ese sentido, de acuerdo con lo dispuesto en el artículo 1498 del Código Civil, se puede indicar que el contrato es conmutativo "cuando cada una de las partes se obliga a dar o hacer una cosa que se mira como equivalente a lo que la otra parte debe dar o hacer a su vez", así mismo, indica este artículo que el contrato será aleatorio si "el equivalente consiste en una contingencia incierta de ganancia o pérdida".

En este sentido, la doctrina ha establecido que un contrato es conmutativo o sinalagmático cuando los dos contratantes están obligados en una relación de 
reciprocidad, es decir, el uno para con el otro; y es aleatorio cuando una o varias personas en atención a una relación negocial se ven obligadas a cumplir ciertas prestaciones para con otra $\mathrm{u}$ otras personas, sin que exista un compromiso por parte de las últimas con las primeras, generando un desequilibrio de las obligaciones (Ripert \& Boulanger, 1963).

Con base en lo mencionado, se puede señalar que el principio de la buena fe realiza una inspiración y desarrollo en la naturaleza conmutativa de ciertos contratos, por cuanto estos estan vinculados jurídicamente a la búsqueda de una reciprocidad y bilateralidad de los beneficios o desventajas dentro del negocio.

En este sentido, hay que señalar que en el contrato conmutativo se hace importante la obligación de lealtad emanado de la buena fe, por cuanto, al existir una reciprocidad en las prestaciones y beneficios, los extremos deben actuar conforme a un favorecimiento recíproco que permita la satisfacción mutua de sus intereses y evitar un eventual abuso de la posición dominante que ostente uno de los extremos contractuales (Neme, 2010).

Por su parte, el contrato aleatorio "depende de un acontecimiento incierto de modo que no es posible apreciar su magnitud hasta que el acontecimiento se verifique" (Meza, 2010, p. 12). En esa medida, esta clase de negocios se funda en aquella propabilidad o improbabilidad de utilidad que las partes asumen al momento de ejecutar el citado contrato, pues el álea que trae consigo el negocio, genera para las partes la incertidumbre sobre la satisfacción o no de sus intereses (Calonge, 1963).

Cabe destacar que, aunque en este tipo de contratos no se haga importante el equilibrio prestacional y favorecimiento recíproco promulgado en los contratos conmutativos, la obligación de diligencia emanada de la buena fe es evidente en esta clase de negocios, por cuanto esta le señala a cada extremo o la parte favorecida por el álea, la manera como debe actuar en la relación jurídica contractual, lo cual si no es atendido por la parte obligada puede recaer en responsabilidad contractual conforme a la buena $\mathrm{fe}^{8}$.

Todo lo anterior, es de recibo en el campo específico del contrato de compraventa de cosa futura, toda vez que el mismo, según lo dispuesto por los artículos 1869 del Código Civil y 917 del Código de Comercio, se clasifica en dos modalidades conformadas por la venta de la esperanza (emptio spei) y la venta de cosa esperada (emptio rei speratae), las cuales se distinguen por su naturaleza aleatoria o conmutativa, respectivamente.

8 Sobre la presencia del principio de la buena fe en los contratos aleatorios, la Sala de Casación Civil de la Corte Suprema de Justicia, trayendo a colación los contratos de juego y de apuesta, señala que ellos están sometidos a una regla inherente a la naturaleza aleatoria, y que consiste en la igualdad de probabilidades o de riesgos entre los contratantes. Por tal razón, "[n]inguno de éstos puede quedar o ser colocado en posición de desventaja respecto de los otros, y es ilícito todo acto o convenio que aumente los riesgos de ganancia o pérdida en perjuicio de una parte y en ventaja de la otra" (CSJ, 1962). 
Sobre la primera modalidad contractual, se afirma que es aquella mediante la cual el comprador se obliga a pagar un determinado precio a cambio de que el vendedor se obligue a transmitirle la propiedad de una cosa que al momento del contrato no existe, pero que puede llegar a existir, y que aun cuando esta no advenga, el comprador está obligado al pago del precio (Ponce, 1973), por tal razón se le considera como aleatoria.

Por otro lado, la segunda especie de contrato de compraventa de cosa futura denominada como venta de la cosa esperada, se cataloga como un negocio jurídico conmutativo, toda vez que ninguna de las partes asume el álea o riesgo que la cosa exista o no (Ponce, 1973).

\section{LA BUENA FE DELIMITA LA MODALIDAD DEL CONTRATO DE COMPRAVENTA DE COSA FUTURA EN EL EVENTO EN QUE LAS PARTES NO LO SEÑALEN EN EL CONTENIDO DEL NEGOCIO JURÍDICO}

La problemática expuesta en el caso objeto de análisis basada en determinar los parámetros jurídicos que sirven para identificar cuando se está ante una compraventa de cosa futura esperada, que atiende a la naturaleza sinalagmática, o ante una compraventa de cosa futura por esperanza, de carácter aleatorio, se puede resolver, no solo atendiendo los criterios de interpretación de los contratos consagrados en los artículos 1618 y siguientes del Código Civil, los cuales son aplicables en materia mercantil en virtud de la remisión expresa del artículo 822 del Código de Comercio, sino también teniendo en cuenta el principio de la buena $\mathrm{fe}^{9}$.

Es indudable que para poder detectar la intención de las partes en el contrato en mención, que permita precisar su modalidad y, por ende, su carácter conmutativo o aleatorio, se requiere de las funciones de integración, interpretación y corrección de la buena fe contractual.

En ese sentido, la función integradora del mencionado principio permite auscultar que las partes estaban obligadas a manifestar o socializar entre sí aquellas informaciones relacionadas con el contexto en el que se desarrollaría el negocio jurídico, con base en los parámetros de claridad, transparencia, oportunidad y suficiencia (Chinchilla, 2009) y teniendo en cuenta la calidad de artifex o lego del extremo negocial que asuma la obligación de informar.

9 A lo anterior se agrega que, tratándose de contratos mercantiles, el juzgador no puede circunscribir su atención exclusivamente a las precitadas reglas hermenéuticas, todas ellas establecidas en el Código Civil, pero aplicables a los negocios jurídicos de esa estirpe, por la integración normativa que dispone el artículo 822 del Código de Comercio, sino que debe igualmente atender los principios -o directrices- que, de manera especial, consagra esta última codificación, entre ellos, por vía de ejemplo, el que aparece entronizado en el artículo 871, conforme al cual, "los contratos deberán celebrarse y ejecutarse de buena fe, y en consecuencia, obligarán no sólo a lo estipulado expresamente en ellos, sino además a todo lo que corresponde a su naturaleza, según la ley, la costumbre o la equidad natural" (se destaca) (CSJ, 2005). 
En ese orden de ideas, en atención a las obligaciones de lealtad y diligencia, los extremos del negocio están en la obligación de informar todos los elementos fácticos que sean relevantes, que permitan establecer si ellas suscribieron una venta de cosa esperada o una venta de la esperanza, como las probabilidades de existencia de la cosa futura objeto de venta, de tal suerte que las partes realicen la valoración previa de los riesgos y de las obligaciones que emanarían del negocio jurídico luego de su perfeccionamiento.

La intensidad de dicha obligación de información se acentúa más cuando el deudor de ella se cataloga como artifex o profesional, toda vez que su acreedor por no tener dicha condición está en una posición de inferioridad, en razón a su desconocimiento. En ese sentido, la buena fe no puede avalar las ganancias que llegue a obtener una parte gracias a la ignorancia de su otro extremo negocial sobre unos aspectos que eran relevantes para determinar el alcance de los riesgos y de las obligaciones del contrato (Neme, 2010).

De otro lado, en cumplimiento de las citadas obligaciones y en razón a la función integradora de la buena fe, las partes se obligan a prever los posibles eventos que a futuro puedan presentarse y que incidan en el desarrollo normal del negocio jurídico. Dicho pronóstico permite precisar la modalidad de contrato de compraventa de cosa futura, en razón a que ello facilita determinar el real alcance de las obligaciones y por lo tanto detectar la existencia o no de algún desequilibrio en la relación contractual que permita inferir el carácter aleatorio o conmutativo del contrato.

En ese sentido, en virtud del principio de la buena fe, se infiere que las partes deben ilustrarse de los riesgos e imprevistos y del alcance de las obligaciones, los cuales ayudan a delimitar si el contrato perfeccionado se cataloga como venta de cosa esperada o venta de la esperanza.

No obstante, puede suceder que durante la transmisión de la información los interesados no precisen con claridad la especie del negocio jurídico objeto de análisis. Ante tal circunstancia, el artículo 1622 del Código Civil, establece la posibilidad de interpretar las conductas que los extremos negociales desplegaron durante todo el iter contractual ${ }^{10}$, las cuales, si se ejecutaron conforme a las obligaciones de lealtad y de diligencia, permitirán determinar la modalidad de contrato de compraventa de cosa futura que acordaron y, así precisar, el alcance de las obligaciones y riesgos que las partes asumieron.

Otra solución que se le puede dar a la problemática surgida gracias a la ambigüedad en las cláusulas que conforman el contenido del contrato en mención y que no dejan delimitar su especie, es acudiendo a la función de interpretación de la buena fe y a lo

10 Código Civil. Artículo 1622. Las cláusulas de un contrato se interpretarán unas por otras, dándosele a cada una el sentido que mejor convenga al contrato en su totalidad. (...) Podrán también interpretarse por las de otro contrato entre las mismas partes y sobre la misma materia. (...) O por la aplicación práctica que hayan hecho de ellas ambas partes, o una de las partes con aprobación de la otra parte. 
dispuesto por el artículo 1624 del Código Civil ${ }^{11}$, la cual establece que tales cláusulas se deberán interpretar en el sentido que favorezca a la parte débil y cuando la vaguedad de las cláusulas se ocasionó en razón a la imposición injustificada de uno de los extremos negociales, la definición de dichas cláusulas se interpretará en contra de la parte que las impuso y a favor del extremo negocial en posición de inferioridad. Lo precedente, según los mandatos del principio de la buena fe, que se orientan al restablecimiento del equilibrio de las prestaciones entre las partes y a la materialización de la justicia contractual (Chamie, 2008).

De otro lado, la función de interpretación de la buena fe permite revisar si las partes realizaron el aludido negocio jurídico, bajo las premisas que las utilidades de ganancia estaban determinadas antes de su perfeccionamiento y la presencia de unas prestaciones equilibradas y un favorecimiento mutuo que vaticinaban la satisfacción recíproca de intereses durante su ejecución. A la luz del inciso primero del artículo 1621 del Código Civil ${ }^{12}$, se infiere que tales premisas se amoldan mejor a la especie de venta de cosa esperada que gira en torno a la conmutatividad y no a la venta de la esperanza que se caracteriza por la aleatoriedad, en razón a que la relación contractual no estaba vinculada a una probabilidad o improbabilidad de ganancia o de pérdida.

Ahora, respecto a la función de corrección emanada del principio de la buena fe, las partes se obligan a abstenerse de realizar aquellas conductas que puedan atentar o afectar la modalidad de compraventa de cosa futura inicialmente pactada, pues ello vulneraría los intereses de alguno de los extremos negociales. Ejemplo de lo anterior, sería aquella alteración, a través de cláusulas abusivas, del carácter conmutativo por aleatorio o viceversa del negocio jurídico (CSJ, 1962) o la adopción de una interpretación al contenido del contrato que sea contraria a la intención de las partes a la luz del artículo 1618 del Código Civil y de su naturaleza jurídica. Tales estipulaciones serían ineficaces por ser contrarias al principio de la buena fe (Arrubla, 2007).

Con base en las reflexiones precedentes sobre la incidencia de la buena fe para fijar la especie de contrato de compraventa de cosa futura, a continuación se analiza el caso concreto que se constituyó en el leitmotiv del presente escrito.

\section{ANÁLISIS DEL CASO CONCRETO}

En el caso se evidencia una gran dificultad para identificar la intención de las partes que permitan establecer la modalidad del contrato de compraventa de frutos futuros que acordaron. Aunado a ello, en el caso no se establecen otros elementos

11 Código Civil. Artículo 1624. No pudiendo aplicarse ninguna de las reglas precedentes de interpretación, se interpretarán las cláusulas ambiguas a favor del deudor. (...) Pero las cláusulas ambiguas que hayan sido extendidas o dictadas por una de las partes, sea acreedora o deudora, se interpretarán contra ella, siempre que la ambigüedad provenga de la falta de una explicación que haya debido darse por ella.

12 Código Civil. Artículo 1621. En aquellos casos en que no apareciere voluntad contraria, deberá estarse a la interpretación que mejor cuadre con la naturaleza del contrato. 
de hecho que permitan definir las conductas que las partes realizaron luego de perfeccionado el contrato objeto de análisis.

No obstante lo anterior, del caso planteado se infiere que el empresario agroindustrial ostentaba la posición dominante en la relación contractual, por ende él fijaba el contenido del contrato de compraventa de frutos futuros. Sumado a ello, se aprecia que hubo ambigüedad en las cláusulas del contenido del aludido negocio jurídico, lo cual no daba claridad sobre su especie. En razón a lo precedente, se puede hacer efectivo lo descrito en el artículo 1624 del Código Civil, en el sentido de interpretar tales cláusulas en contra del empresario agroindustrial, toda vez que él las impuso de manera injustificada en el contenido del contrato.

En ese orden de ideas, se concluye que la interpretación que le favorece al comprador, que ostenta la condición de parte débil en el contrato, sería aquella de reconocer que el contrato de compraventa de frutos futuros se realizó bajo la especie de venta de cosa esperada, toda vez que esta se considera de naturaleza conmutativa; $\mathrm{y}$, por tal razón, el advenimiento de los frutos no se considerarían como algo derivado del azar o de la suerte, sino que era muy probable su existencia, gracias a la intervención no solo de la naturaleza sino del vendedor artifex. Dicha interpretación es acorde con el principio de la buena fe, toda vez que esta persigue la preservación del equilibrio prestacional y la justicia contractual (Chamie, 2008).

Otros argumentos jurídicos que soportan la afirmación que el contrato que se planteó en el caso hipotético, es de la especie de venta de cosa esperada, se basa en que el empresario agroindustrial, quien ostentaba la condición de artifex en el sector de la agroindustria, no atendió los mandatos del principio de la buena fe, toda vez que incumplió su obligación de informar al comprador de los posibles riesgos que eventualmente podrían afectar los cultivos, por ejemplo, la propagación del hongo en el sector donde se encontraba la plantación y el alcance de las obligaciones que dicho sujeto asumiría al suscribir el contrato, todo ello con el fin de que el comprador, siendo consciente de todos los pormenores del negocio, emitiera su consentimiento dirigido a la realización o no del contrato.

En razón a lo precedente, el comprador está legitimado para incoar la acción resolutoria o de cumplimiento $\mathrm{y}$, en cualquiera de los dos, reclamar al vendedor la indemnización de perjuicios por el daño causado, de acuerdo con lo estipulado en el artículo 870 del Código de Comercio ${ }^{13}$.

En ese sentido, señalar que el negocio jurídico de venta de cosa futura entre la empresa agroindustrial y el comprador se adecua a la modalidad emptio spei y por lo tanto aleatorio, implicaría que las partes desde un principio asumían el riesgo de incertidumbre de ganancia o utilidad en igualdad de probabilidades (CSJ, 1969), atendiendo la interpretación del artículo 1498 del Código Civil, que en el caso

13 Código de Comercio. Artículo 870. En los contratos bilaterales, en caso de mora de una de las partes, podrá la otra pedir su resolución o terminación, con indemnización de perjuicios compensatorios, o hacer efectiva la obligación, con indemnización de los perjuicios moratorios. 
planteado no se estructuraba, toda vez que la vendedora en razón a su condición de profesional debió conocer que los cultivos estaban en amenaza de un hongo que podría afectar la producción o si conocía de tal novedad en la zona, debió informar de dicha situación al comprador para que él decidiera si compraba o no la cosecha futura de frutos con los riesgos que ello implicaba.

Con base en lo señalado en el párrafo precedente, el vendedor artifex hizo caso omiso a las obligaciones de lealtad y diligencia que integran el contenido del contrato de compraventa de cosa futura en razón a la buena fe. Es por ello que sería contrario al citado principio señalar que el contrato se amoldaba a la especie de venta de la esperanza y, en razón a su carácter aleatorio, trasladar al comprador todos los riesgos del negocio, como la pérdida o la producción baja de los frutos objeto de venta por el hongo que afectó a los cultivos, sin la posibilidad de devolución del precio.

Para comprender lo anterior, se debe tener presente que el comprador desde un comienzo realizó el contrato de compraventa de cosa futura, en razón a la profesionalidad y a la pericia de su vendedor en el sector de la agroindustria, lo cual le generó a él la confianza de una alta probabilidad de ganancia, delimitándose a la especie de venta de cosa esperada y, por ende, el carácter conmutativo del negocio, pues tanto el vendedor como el comprador tenían una seguridad meridiana de las utilidades que iban a recibir durante la relación contractual.

Sin perjuicio de lo señalado, es importante aclarar que el contrato de compraventa de cosa futura bajo la modalidad de venta de la esperanza, no es ajena a los postulados que emanan de la buena fe contractual, pues dicho principio le exige a los extremos negociales la abstención de realizar conductas dirigidas a alterar la incertidumbre o aleatoriedad del negocio.

En ese sentido, si el contrato suscrito hubiese sido emptio spei y el empresario agroindustrial sabía desde antes de realizar el negocio jurídico de la presencia del hongo en los cultivos y lo oculta a su comprador, estaría obrando de manera contraria a la obligación de lealtad, que se deriva del principio de la buena fe, y por lo tanto deberá responder por los daños causados a su otro extremo negocial a título de dolo con base en lo señalado en el artículo 1515 del Código Civil.

La misma consecuencia jurídica sucedería en aquel evento en que, no obstante que las partes perfeccionaron un contrato de compraventa de frutos futuros bajo la modalidad de venta de la esperanza, el vendedor no cumple con su obligación de cultivar el predio (Calonge, 1963, citado en Wetter, 1910, p. 12-14) o que acaecida la esperanza con la existencia de los frutos, el vendedor no cumple con la obligación de entrega de los mismos al comprador. Por otra parte, el comprador está en la obligación de realizar el pago del precio en todo momento, aun en el caso en que no se haya efectuado la producción de los frutos, o habiéndose producido, corra con el riesgo de que la cantidad o calidad no sea la esperada, ya sea porque existió un breve deterioro de la cosa, o una excelente calidad y cantidad de esta (Calonge, 1963). 


\section{CONCLUSIONES}

En el contexto del derecho privado colombiano, es evidente que la buena fe objetiva, como elemento ético-social en general, ejerce una fuerza vinculante y normativa en todo el iter de las relaciones jurídico-negociales, ordenando a quienes participan en la relación contractual asumir una conducta leal y diligente conforme a la función económico social del negocio jurídico concreto.

En ese sentido, el aludido principio cumple una función interpretativa, integradora y correctiva, las cuales permiten resolver las controversias que se susciten entre las partes, en razón a una inconsistencia (ambigüedad, vacio, cláusula abusiva, entre otros) en el contenido del negocio jurídico o por una labor hermenéutica inadecuada por alguno de los intervinientes en el contrato, los cuales podrían atentar contra su naturaleza jurídica y, de contera, afectar los intereses de alguno de los extremos negociales.

Atendiendo las citadas funciones, se estableció que a partir de la buena fe contractual surgen las obligaciones de lealtad y diligencia, las cuales son asumidas por las partes, independientemente que no se lleguen a estipular de manera expresa en el contenido del negocio jurídico. Tales obligaciones se entrelazan en la obligación de información, la cual emana de la obligación de lealtad, y tienen efecto vinculante en todo el iter contractual.

El cumplimiento cabal de las mencionadas obligaciones por los extremos negociales, que se concretizan en la obligación de información, le permitirán a ellas conocer todos los pormenores del negocio, determinar el alcance de los riesgos y de las obligaciones que ellas asumirían, todo lo cual facilita la identificación del carácter aleatorio o conmutativo del contrato.

Ahora, es importante señalar que la intensidad de la obligación de información varía dependiendo de la calidad del sujeto, pues si éste ostenta la condición de artifex o profesional, en razón a su oficio, dicho sujeto deberá socializar con mayor claridad, transparencia, oportunidad y suficiencia todos los detalles del contrato a su otro extremo, de tal suerte que este último declare su voluntad con pleno conocimiento de causa y sin ningún margen de error.

Todo lo anterior es de recibo en el campo específico del contrato de compraventa de cosa futura, la cual, según lo dispuesto por los artículos 1869 del Código Civil y 917 del Código de Comercio, se clasifica en dos modalidades conformadas por venta de cosa esperada (emptio rei speratae) o venta de la esperanza (emptio spei).

De otro lado, se planteó un caso, a través del cual se evidenció que existe un problema jurídico para determinar los parámetros que permiten delimitar las aludidas especies de contrato de compraventa de cosa futura, cuando las partes no cumplieron con su carga de claridad de señalarlo en el contenido del citado negocio jurídico.

Ante dicha problemática, se expuso como solución acudir al principio de la buena fe como parámetro jurídico que permitiría identificar cuando se está ante una compraventa de cosa futura esperada, que atiende a la naturaleza sinalagmática, o 
ante una compraventa de cosa futura por esperanza, que se cataloga como aleatoria. Lo anterior en concordancia con los criterios de interpretación de los contratos consagrados en los artículos 1618 y siguientes del Código Civil, los cuales son aplicables en materia mercantil en virtud de la remisión expresa del artículo 822 del Código de Comercio.

Con base en tales premisas, y en especial por las funciones de la buena fe contractual y las obligaciones de lealtad y diligencia que emanan del mencionado principio, se señaló que en el caso planteado el contrato de compraventa de frutos futuros se adecuaba a la especie de venta de cosa futura esperada y por lo tanto su naturaleza era conmutativa.

Dentro de las razones jurídicas que soportan la afirmación antes descrita, está aquella que se funda en lo dispuesto en el artículo 1624 del Código Civil, la cual señala que ante la presencia de cláusulas ambiguas en un contrato, las cuales fueron impuestas por una de las partes de manera injustificada, el contenido de las mismas se debe interpretar en contra de dicha parte y en beneficio de su otro extremo negocial que ostenta la condición de parte débil.

En ese sentido, como el empresario agroindustrial fijó de manera unilateral e injustificada el contenido del contrato, atendiendo su posición dominante en la relación contractual, la interpretación que le resulta adversa, pero a su vez favorable para el comprador, es aquella en que se califique al negocio jurídico en la modalidad de venta de cosa esperada. Dicha interpretación es conforme con el principio de la buena fe, pues se orienta a la conservación del equilibrio prestacional y a la justicia contractual.

El otro argumento que justifica la solución planteada, se basa en que el empresario agroindustrial no cumplió con los postulados de la buena fe al momento de realizar el negocio jurídico con su comprador, toda vez que desconoció las obligaciones de lealtad y diligencia que surgen gracias a la función integradora del citado principio e hizo caso omiso al modelo de artifex, al no informar al comprador de los posibles riesgos que casualmente podrían perturbar los cultivos, por ejemplo la difusión del hongo en la zona donde se encontraba la plantación; y el alcance de las obligaciones que dicho sujeto asumiría al suscribir el contrato, todo ello con el fin de que el comprador, siendo consciente de todos los pormenores del negocio, emitiera su consentimiento dirigido a la realización o no de éste.

En ese orden de ideas, el comprador está habilitado para instaurar la acción resolutoria o de cumplimiento y, en cualquiera de los dos, solicitar al empresario agroindustrial la indemnización de perjuicios por el daño causado, atendiendo lo dispuesto en el artículo 870 del Código de Comercio.

En ese sentido, señalar que el negocio jurídico de venta de cosa futura entre la empresa agroindustrial y el comprador se adecua a la modalidad emptio spei y por lo tanto aleatorio, sería contrario al principio de la buena fe, pues no se estaría preservando el equilibrio prestacional y la justicia contractual, pues de la naturaleza del negocio jurídico no se desprende que el comprador quiso asumir el álea de que los frutos existieran o no en el futuro. 


\section{REFERENCIAS}

Arrubla, J. A. (2007). Contratos mercantiles. Teoría general del negocio mercantil (t. I). Medellín: Biblioteca Jurídica Diké.

Betti, E. (1969). Teoría general de las obligaciones (t. I). Madrid: Editorial Revista de Derecho Privado.

Calonge, A. (1963). La compraventa civil de cosa futura desde Roma hasta la doctrina europea actual. Salamanca: Talleres Gráficos Imprenta Núñez.

Chamie, J. (2008). Equilibrio contractual y cooperación entre las partes: El deber de revisión del contrato. Revista de Derecho Privado, 14, 113-138.

Chinchilla, C. (2011). El deber de información contractual y sus límites. Revista de Derecho Privado, 21, 327-350. Universidad Externado de Colombia.

Código de Comercio Colombiano. Decreto Extraordinario 410 de 1971. Junio 16 de 1971 (Colombia).

Congreso de la República de Colombia. (1887). Código Civil. Ley 57 de 1887.

Corte Constitucional. Sentencia N. T-487 (M.P. Alejandro Martínez Caballero, 11 de agosto de 1992).

Corte Suprema de Justicia. Sala de Casacion Civil. Sentencia. (M. P. Enrique López de la Pava, 13 de diciembre de 1962).

Corte Suprema de Justicia. Sala de Casacion Civil. Sentencia Ref. Expediente No. 6146 (M. P. Carlos Ignacio Jaramillo Jaramillo; 2 de agosto de 2001).

Corte Suprema de Justicia. Sala de Casacion Civil. Sentencia Ref. Expediente No. 7504 (M. P. Carlos Ignacio Jaramillo Jaramillo, 28 de febrero de 2005).

Corte Suprema de Justicia. Sala de Casacion Civil. Sentencia Ref. Expediente No. 05001-3103-009-2001-00263-01 (M.P. William Namén Vargas, 19 de octubre de 2009).

Cortés, É. (2009). La culpa contractual en el sistema jurídico latinoamericano. Bogotá: Universidad Externado de Colombia.

Díez-Picazo \& otros. (2002). Los principios del derecho europeo de contratos. Madrid: Civitas.

Gandolfi, G. \& otros. (2009). Código europeo de contratos. Bogotá: Temis.

Hinestrosa, F. (1986). Funciones, límites y cargas de la autonomía privada. En Estudios de derecho privado. Bogotá: Universidad Externado de Colombia.

Hinestrosa, F. (2002). Tratado de las obligaciones. Concepto, estructura, vicisitudes. Bogotá: Universidad Externado de Colombia.

Instituto Internacional para la Unificación del Derecho Privado (UNIDROIT). (2010). Roma.

Jordano, F. (1987) La responsabilidad contractual. Madrid: Editorial Civitas S.A.

Larenz, K. (1958). Derecho de las obligaciones (t. I). Madrid: Editorial Revista de Derecho Privado. 
Larenz, K. (1978). Derecho civil. Parte general. Madrid: Editorial Revista de Derecho Privado.

Meza, R. (2010). Manual de derecho civil, de las fuentes de las obligaciones (t. I. $7^{\mathrm{a}}$ ed.). Chile: Jurídica de Chile.

Neme, M. L. (2006). El principio de buena fe en materia contractual en el sistema jurídico colombiano. Revista de Derecho Privado. Numero 11. Universidad Externado de Colombia, 79-125.

Neme, M. L. (2009). Buena fe subjetiva y buena fe objetiva. Equívocos a los que conduce la falta de claridad en la distincion de tales conceptos. Revista de Derecho Privado, 17, 45-76. Universidad Externado de Colombia.

Neme, M. L. (2010). La presunción de buena fe en el sistema jurídico colombiano: una regla cuya aplicación tergiversada desnaturaliza el principio. Revista de Derecho Privado, 18, 65-94. Universidad Externado de Colombia.

Neme, M. L. (2010). La buena fe en el derecho romano. Extension del deber de actuar conforme a buena fe en materia contractual. Bogota: Universidad Externado de Colombia.

Ponce, F. (1973). La venta de cosa futura. Revista Jurídica. Anuario del Departamento de Derecho de la Universidad Iberoamericana, 5. ISSN 1405-0935.

Ripert, G., \& Boulanger, J. (1963). Tratado de derecho cívil según el tratado de derecho de planiol. (D. G. Daireaux, trad.) Buenos Aires: La Ley.

Rogel, C. (1975). La compraventa de cosa futura. L. Diez-Picazo (Ed.). Bolonia: Publicaciones del Real Colegio de España.

San Martín, L. C. (2011). Sobre la naturaleza jurídica de la ‘cooperación’ del acreedor al cumplimiento de la obligación. La posición dinámica del acreedor en la relación obligatoria, como sujeto no sólo de derechos, sino también de cargas y deberes. Revista de Derecho Privado, 21, 273-325. Universidad Externado de Colombia.

Soto, C. A. (2009). La autonomía privada y la buena fe como fundamento de la fuerza obligatoria del contrato. En Soto, C.A., y Mosset, J. El contrato en una economía de mercado. Bogotá D.C.: Pontificia Universidad Javeriana, Facultad de Ciencias Jurídicas.

Vargas, C. (2001). Aspectos controvertidos de la responsabilidad contractual. Revista Vniversitas, 101, 495. Universidad Javeriana.

Viehweg, T. (1964). Tópica y jurisprudencia. Madrid: Taurus, S. A. 